\title{
STRESS ANALYSIS OF TWO DIFFERENT ATTACHMENTS FOR A SINGLE IMPLANT RETAINED MANDIBULAR OVERDENTURES IN THE MIDLINE (IN VITRO STUDY)
}

\author{
Ahmed H. M. Rashad* , Hamdi Abo Alfotouh Hamed ${ }^{* *}$ and Nouran Mahmoud Abdel Nabi ${ }^{* * *}$
}

\begin{abstract}
Objective: aiming to record the induced micro-strain around one installed implant in the midline of a completely edentulous mandible using strain gauges utilizing an implant retained overdenture with two different types of attachments Ball and CMLOC attachment.

Materials and methods: An acrylic resin test resin test model representing a completely edentulous lower arch was used.The distal part of the residual ridge was covered with silicon based soft liner to stimulate the mucopcriostcum. Steps of complete denture fabrication was followed in conventional manner. Duplication of the finished denture was carried out to be used as a surgical stent .A single implant installed in the midline. After the implant was installed in the acrylic resin cast, the ball attachment was screwed to the implant. The denture was prepared for the direct pick up procedure, the same procedure repeated for CM IOC attachment. Four strain gauges around were installed on all surfaces of implant (Buccal. Lingual. Mesial .Distal) to monitor the effect of the applied loads vertical on the two types of attachments. A vertically load applied of $100 \mathrm{~N}$ static load was applied by using universal testing machine at two different sites (unilateral left first molar and bilaterally).
\end{abstract}

Results : When the load applied unilaterally on the left side ,it was shown that the single implant retained overdenture with the Ball attachment has shown higher microstrain than the CMLOC ,average microstrain for Ball (391.26) N , and for CMLOC (223.22) N . When the load applied bilaterally, the single implant retained overdenture with the CMLOC (269.05)N attachment has shown higher microstrain than the Ball (106.79) N.

Conclosion: It can be concluded from this invitro study that the newly introduced attachment the CMLOC lends to show a better performance with regards to the micro-strains induced around the implants. On the other hand the Ball attachments tends to show more micro-strain around the implants.

* Oral Implantology Department, Faculty of Dentistry Cairo University, Egypt

** Removable Prosthodontics Department, Faculty of Dentistry Cairo University, Egypt 


\section{INTRODUCTION}

Severe atrophy of the alveolar process and underlying basal bone often results in several problems with mandibular denture. These problems include insufficient retention of the lower denture, intolerance to loading by the mucosa, pain, difficulties with eating and speech, loss of soft tissue support, altered facial appearance and reduced quality of life in this specific patient group. These problems are a challenge for the prosthodontist and surgeon $^{(1,2)}$.

There are several types of attachment that can be used to retain an implant over denture, they are mainly classified into splinted attachments such as bar attachments or un-splinted attachments such as ball or locator attachment. The un-splinted attachments have been more commonly used than the splinted attachment owing to the smaller space requirements within the prosthesis, ease of cleaning, more economical, and lower sensitivity to techniques ${ }^{(3,4)}$.

Ball and socket attachment has been the most popular un-splinted attachment to retain a mandibular overdenture, because its simplicity and cost effectiveness $\cdot$ A newly introduced attachment made from polyetherketoneketone (PEKK) which is a member of the polyaryletherketones (PAEKs). Polyaryletherketones have the advantage of high chemical and mechanical resistance to wear and high tensile, fatigue and flexural strengths . According to the manufacturer Cendres and Metaux, Polyetherketoneketone has $80 \%$ higher compressive strengths than other PAEK materials ${ }^{(5)}$.

Excessive stresses transmitted to the underlying bone can result in bone resorption consequently resulting in implant failure The distribution of stresses around an implant would depend upon many factors such as; implant design and diameter, abutment length, angulation, and its relation with the implant platform ${ }^{(6,7)}$.

Various methods have been used to analyze the transmission of stresses to the underlying bone among them are; photo elastic, strain gauge and finite element analysis. Photo elastic analysis is of low cost, it's a simple method, and it provides a qualitative analysis of the stresses present in the bone but doesn't allow an accurate measurement ${ }^{(8)}$.

There has been a major contraversary in the literature to the number of implants required to support an overdenture, 4, 3, 2 or even a single implant in the midline to improve function and esthetics of the patient. A single implant retained overdenture has proved to be a reliable and cost effective treatment option for eldery patient ${ }^{(9,10)}$.

The question now arises for a single implant retained mandibular overdenture, which attachment will induce the minimum microstrain to the underlying implant?

\section{AIM OF THIS STUDY}

The aim of this in vitro study is to compare the induced micro-strain for a single implant retained mandibular overdenture with two different types of attachments Ball and CMLOC attachment.

\section{MATERIALS AND METHODS:}

\section{Acrylic model construction:}

An acrylic resin model was fabricated from a mandibular completely edentulous simulating a clinical condition. Acrylic model was fabricated according to the following steps; A final impression Fig. (1) using silicon impression material* of completely edentulous ridge was recorded then molten wax was then poured into the impression to produce a wax cast . After wax hardening inspection for any discrepancy was adjusted". The waxed cast

\footnotetext{
* Elite dental stones Zhermack- BadiaPolesine (Rovigo)-Italy.
} 


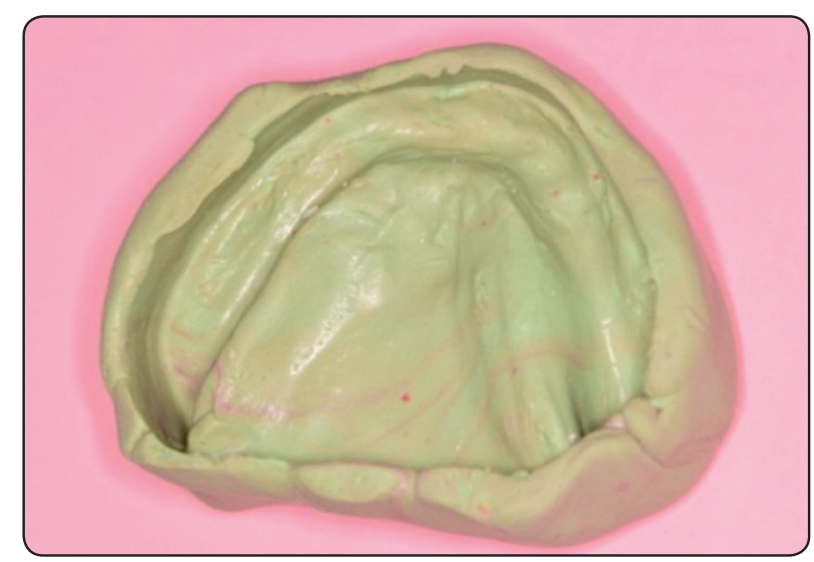

Fig. (1): Final impression using silicon impression material

was then flasked and wax elimination was carried out. The created mold was packed with heat polymerized acrylic resin, and then cured by using long curing cycle 8 hours at $70^{\circ} \mathrm{C}$. The flask was left to bench cool for two hours before deflasking, the model is finished and polished ${ }^{* *}$ Fig. (2).

\section{Simulation of the artificial mucosa:}

An index of the acrylic completely edentulous cast was made using putty impression material. The posterior ridge distal to the second premolar was modified by reducing the distal area of the crest of the ridge using a round bur on the buccal and

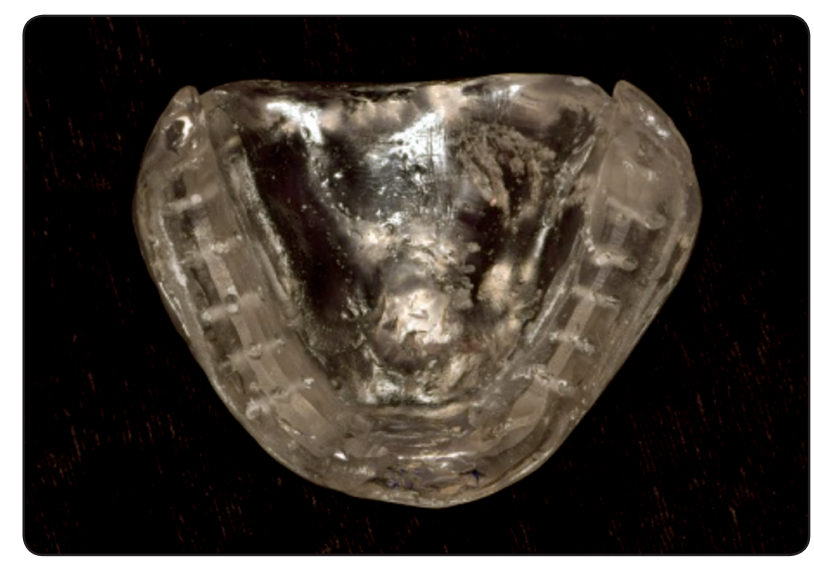

Fig. (2): Acrylic resin model lingual surfaces then the soft molloplast B was used to reline the reduced area. The reduced edentulous area was painted by adhesive $\mathrm{e}^{* * *}$ before application of molloplast B Fig.(3) . The index wax then used for the molloplast $\mathrm{B}$ that to cover the ridge.

\section{Implant installation :}

The lower finished denture was then duplicated

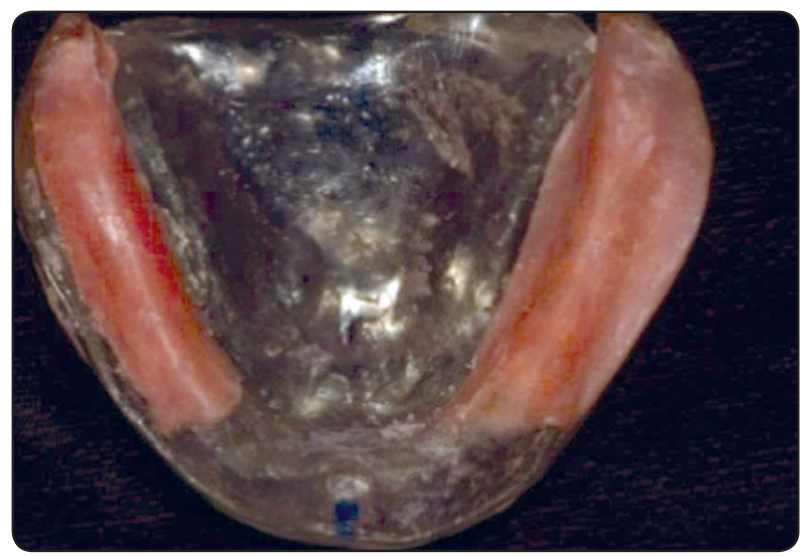

Fig. (3): Application of soft molloplast B

into an acrylic resin stent. This stent would be used as a surgical stent to guide for implant installation .The stent was then modified by placing holes around centeral incisor area. Drilling was carried out by using a round bur, then the midline was identified by the initial drill, then intermediate drill and then final drill was $3.7 \mathrm{~mm}$ for implant ${ }^{*}$ size $(3,9 \times 10) \mathrm{mm}$. length of drilling was identified by graduation of the drill.

The implant was the attached to the surveyor Fig. (4) Corresponding to the drilled hole, and then a mix of self cure acrylic resin was added to the drill hole, and then the implant was placed.

\footnotetext{
* Acrostone-Heat polymerized denture base material-England

** Putty c-silicone impression material Zermack-Badiapolesine (Rovigo)-Italy. *** Primo, DETAX, Voco, 3002-Germany
} 


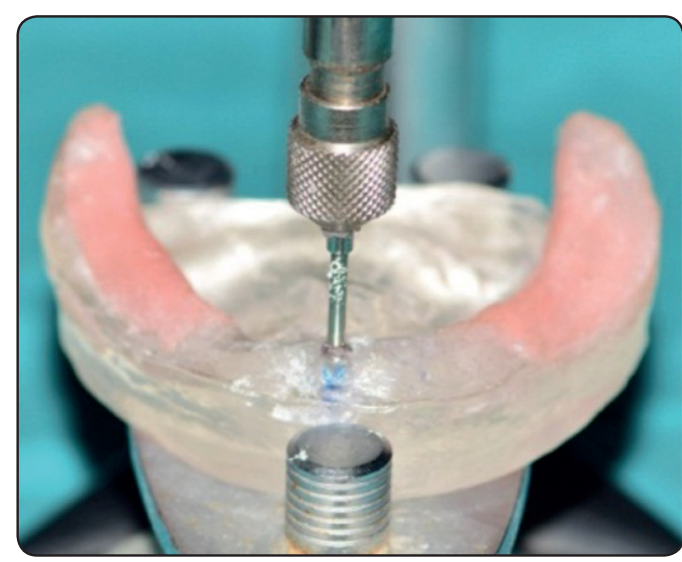

Fig. (4): Implant attached to the surveyor

\section{The pick up:}

After the implant was installed in the acrylic resin cast, the ball attachment of (group 1) (Mandibular overdenture retained with Ball abutment) was screwed to the implant. A mix of auto polymerized acrylic resin was then applied on the fitting surface of the denture opposite to the abutment. The denture base was then seated on the model and the attachment, then after complete setting of the acrylic resin, the denture with the housing and nylon cap in the fitting surface was finished and polished

\section{Preparation of the model for installation of the strain gauges:}

The preparation was of a box shape with a thickness of $1 \mathrm{~mm}$ of acrylic resin around the implant, having four prepared surfaces; Buccal (B), Lingual (L), Mesial (M), and Distal (D) Fig. (5). The four prepared surfaces had to be flat and parallel to the long axis of the implant each prepared surface had to be smoothened using sand paper before installation of the strain gauges to avoid incremental strains.

\section{Vertical loading (unilateral and bilateral)s:}

The overdenture retained by ball attachment

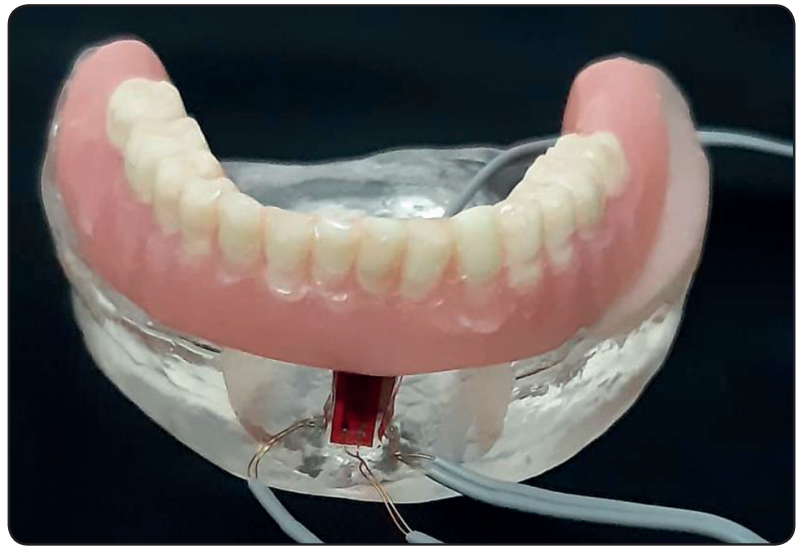

Fig. (5) : Strain gauges around the implant

was seated on acrylic model . A $100 \mathrm{~N}$ load applied unilaterally at centeral fossa of right first molar, then application of metal rod on right and left first molar in central fossa).

\section{Load application and strain recording measure- ment}

LLOYD LR5K universal testing machine was used . The compressive load was $100 \mathrm{~N}$ static load, with cross head speed $0.5 \mathrm{~mm} / \mathrm{sec}$ and the machine was computer controlled by the NEXYGEN* software which permits the collection of dat. Numerical data were represented by mean and standard deviation (SD) values and were explored for normality by checking the data distribution, calculating the mean and median values and using KolmogorovSmirnov and Shapiro-Wilk tests. Data showed nonparametric distribution so; they were analyzed using Mann-Whitney U test for intergroup comparisons and Friedman's test of repeated measures followed by Dunn's post hoc test for intragroup comparisons. The significance level was set at $\mathrm{P} \leq 0.05$ for all tests. Statistical analysis was performed with IBM $®$ SPSS ${ }^{\circledR}$ (SPSS Inc., IBM Corporation, NY, USA) Statistics Version 25 for Windows.

* Nexygen plus materials test and data anaylsis software. Flexible software, allows the operator to control and monitor all aspects of the system from a single front end,ensuring fast, reliable and powerful testing and data analysis for tensile, compression, peeling,tearing ,creep,relaxation and flexural test applications. 


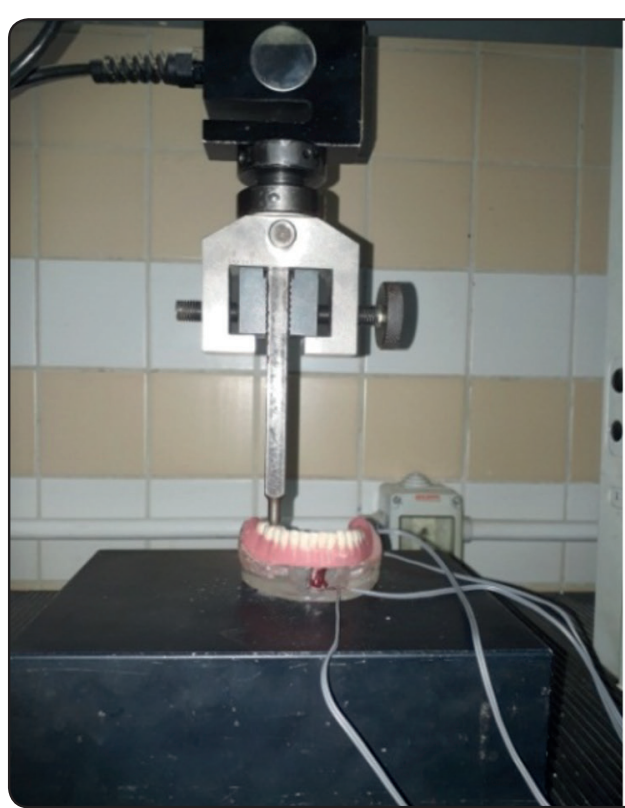

Unilateral left first molar

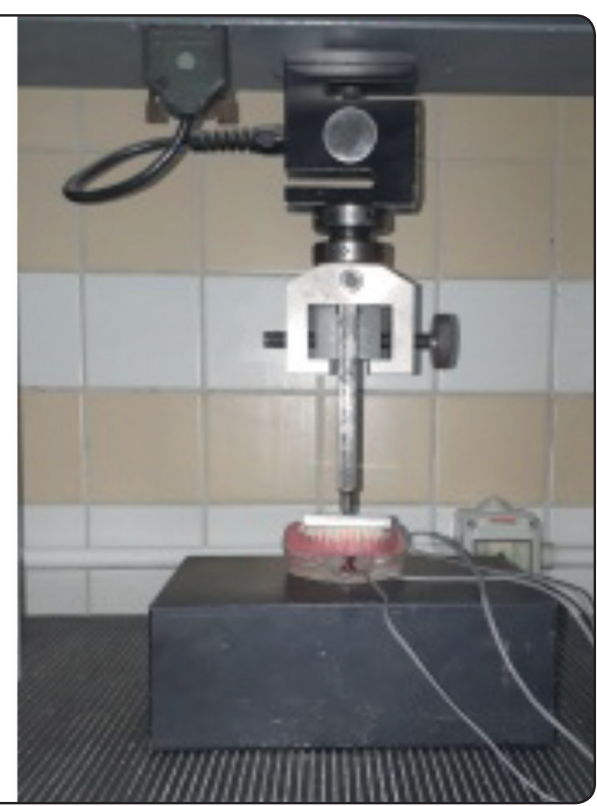

Bilateral Right, left molar

\section{RESULTS}

\section{1- Comparisons of micro-strain $(\mathrm{N})$ with unilat- eral load}

\section{Unilateral load at the Left side:}

When comparing the mean microstrain recorded at each of the four surfaces; Buccal, lingual, right and left, for the two attachments, Ball and CMLOC it was founded that ,there was a statistically significant higher mean microstrain for the Ball attachment at the three surfaces; buccal (P-value $<0.001$ ), lingual
(P-value $<0.001)$ and left surface (P-value $<0.001)$, except for the right surface there was no significant difference in the mean microstrain recorded between the Ball and CM LOC attachment.

The Ball attachment (391.26 \pm 111.77 ) have shown a statistically significant higher average microstrain than the CM LOC attachment (223.22 \pm 69.56$)$.

\section{2- Comparisons of micro-strain $(\mathrm{N})$ with bilat- eral load}

With bilateral load, when comparing the mean microstrain recorded at each of the four surfaces;

TABLE (1) Mean, Standard deviation (SD) values of micro-strain (N) in both groups with left unilateral load.

\begin{tabular}{|c|c|c|c|c|}
\hline \multirow{2}{*}{$\begin{array}{c}\text { Direction } \\
\text { of load }\end{array}$} & \multirow{2}{*}{$\begin{array}{c}|c| \\
\text { Surface of measurement }\end{array}$} & CM LOC & Ball and socket & \multirow{2}{*}{ P-value } \\
\cline { 2 - 5 } & Buccal & $13.44 \pm 8.54^{\mathrm{C}}$ & $157.72 \pm 58.87^{\mathrm{C}}$ & $<0.001^{*}$ \\
\cline { 2 - 5 } & Right & $179.68 \pm 102.60^{\mathrm{B}}$ & $224.20 \pm 129.30^{\mathrm{C}}$ & $0.145 \mathrm{~ns}$ \\
\cline { 2 - 5 } & Lingual & $532.82 \pm 222.84^{\mathrm{A}}$ & $809.64 \pm 373.93^{\mathrm{A}}$ & $<0.001^{*}$ \\
\cline { 2 - 5 } & Left & $124.77 \pm 84.08^{\mathrm{B}}$ & $373.47 \pm 193.09^{\mathrm{B}}$ & $<0.001^{*}$ \\
\cline { 2 - 5 } & Average & $223.22 \pm 69.56^{\mathrm{B}}$ & $391.26 \pm 111.77^{\mathrm{B}}$ & $<0.001^{*}$ \\
\hline
\end{tabular}


TABLE (2): Mean, Standard deviation (SD) values of micro-strain (N) in both groups with bilateral load

\begin{tabular}{|c|c|c|c|c|}
\hline \multirow{2}{*}{ Direction of load } & \multirow{2}{*}{$\begin{array}{c}\text { Surface of } \\
\text { measurement }\end{array}$} & Ball and socket & Micro-strain (mean \pm SD) & \multirow{2}{*}{ P-value } \\
\cline { 2 - 5 } & Buccal & $20.83 \pm 24.99^{\mathrm{C}}$ & $38.45 \pm 15.99^{\mathrm{B}}$ & $\mathrm{p}<0.001^{*}$ \\
\cline { 2 - 5 } & Right & $132.67 \pm 56.12^{\mathrm{A}}$ & $10.86 \pm 6.13^{\mathrm{B}}$ & $\mathrm{p}<0.001^{*}$ \\
\cline { 2 - 5 } & Lingual & $56.00 \pm 66.25^{\mathrm{BC}}$ & $458.28 \pm 204.43^{\mathrm{A}}$ & $\mathrm{p}<0.001^{*}$ \\
\cline { 2 - 5 } & Left & $217.67 \pm 116.72^{\mathrm{A}}$ & $568.62 \pm 256.80^{\mathrm{A}}$ & $\mathrm{p}<0.001^{*}$ \\
\cline { 2 - 5 } & Average & $106.79 \pm 41.29^{\mathrm{AB}}$ & $269.05 \pm 120.39^{\mathrm{A}}$ & $\mathrm{p}<0.001^{*}$ \\
\hline
\end{tabular}

Different superscript letters within the same vertical column indicates a statistically significant difference*; significant (p $\leq$ $0.05)$ ns; non-significant ( $p>0.05)$

Buccal, lingual, right and left, for the two attachments, Ball and CM LOC it was founded that, there was a statistically significant higher mean microstrain for the CM LOC attachment at the buccal (P-value $<0.001)$, lingual (P-value $<0.001)$ and left surface $(\mathrm{P}$-value $<$ $0.001)$.

The mean microstrain recorded at the right side was statistically significant higher with the Ball attachment $(132.67 \pm 56.12)$ then the CM LOC (10.86 \pm 6.13$)$.

The CM LOC attachment (269.05 \pm 120.39$)$ have shown a statistically significant higher average microstrain than the Ball attachment (106.79 \pm 41.29$)$

\section{DISCUSSION}

\section{Discussion of Methodology:}

An in vitro study rather than an invivo was selected to compare the induced mcrostrains because laboratory studies are more easily controlled, more practical and can yield more accurate results especially when the experiments are concerned with stress analysis .Although there is a difficulty in reproducing the physiology of the oral masticatory system, many authors used the invitro studies to compare stresses induced in the supporting structures of implant supported overdenture prostheses ${ }^{(11,12)}$.
An acrylic mandibular test model was to stimulate the clinical condition in this invitro study. (El-Abd et al., 2018, Rady et al., 2017) ${ }^{(13)}$. The acrylic resin was the material of choice for the construction of experimental model as acrylic resin has a modulous of elasticity very close to that of compact bone (Harder et al., 2011) ${ }^{(14)}$. This mandibular test model remained constant through out the experiment, in order to control the variables. The physical properties of acrylic resin do not simulate the complex nature of living bone, as the mechanobiology of bone and osseointegration, so the results of this study are only descriptive.

The advantages of Molloplast $-\mathrm{B}$, ensured that it would remain constant throughout the experiment owing to its dimensional stability (Rady et al., 2017) ${ }^{(15)}$. A single implant retained mandibular overdentures have proved to be a cost effective simple treatment modality especially in eldery patients (Mahoorkar et al., 2016, Kanazawa et al., 2018). ${ }^{(16,17)}$ Implant success and prosthetic outcome and patient satisfaction are comparable whether one or two-implants are used for support of mandibular overdentures. In addition to cost effectiveness of the single implant overdenture, there are potential surgical advantages as well (Kanazawa et al., 2018) (17) that was the reason a single implant installed in the mid line of a completely edentulous 
mandible. The ball attachment has been used as the gold standard in this invitro study owing to its several advantages; simplicity in design, ease of use and maintenance, low cost, varying degrees of retention, wide range of movement, great patient satisfaction and used to increase retention of implant complete and partial overdenture prostheses with regard to optimizing stress and minimizing denture movement (Cheng et al., 2012) ${ }^{(18)}$.

The Cendres Metaux Locator (CM-LOC) attachment was recently introduced with its PEKK matrix as an alternative to the ball attachment. It is claimed that its new design and materials may significantly reduce wear and subsequently less matrix exchange and less maintenance However, the clinical performance of this attachment regarding single implant overdenture is not tested yet (Naguib et al., 2019) ${ }^{(19)}$.

Unilateral and bilateral forces were applied to central fossa of the first molar of mandibular overdenture retained by implant as the first molar is considered (Kono et al., 2014, ELsyad et al.2016, Rady and Abdel Nabi 2017) ${ }^{(20,21,22)}$.

\section{Discussion of results:}

When comparing the mean microstrain between the ball and the CM LOC attachment when subjected to unilateral loading, it was found that the overdenture with the ball attachment have recorded a statistically significant higher mean microstrain than the overdenture retained with the CM LOC attachment, this would mainly be due to the absence of vertical resiliency of the ball attachment and also the ball and nylon matrix would contact each other without intervening space. This comes in agreement with ( ELAbd et al., 2017) ${ }^{(23)}$, this study concluded that high stress concentration were recorded with ball attachment on the loading side .

On contrast the CM LOC attachment has a PEKK matrix design with a slot in the matrix, this slot will expand upon loading, thus resulting in more vertical resiliency that would allow movement of the prosthesis .During unilateral loading the overdenture have experienced a slight rotation, resulting in inducing more micro-strain to the implant when analyzing the micro-strain recorded by both types of attachment it was found that the ball attachment have induced a higher microstrain during disengagement than the CM LOC. The reason for this would be the difference in the properties of the nylon cap, and the PEKK cap. The nylon cap induce more stresses during disengagement than the PEKK which would disengage faster and so transmitting less stresses to the underlying implants. There tends to be a correlation between release period at which an attachment loses retention and the amount of stresses transferred to the abutments, the faster the attachment releases the less stress is placed on the abutments or implants.

When applying unilateral load at the left side, there was no significant difference in the mean microstrain recorded between the Ball and $\mathrm{CM}$ LOC attachment at the right side only while all other surfaces were statistically significant. An explanation for this would be that both attachments will tend to rotate when load around a single fulcrum line when load is applied is applied and so would tend to disengage at the side opposite to the load applied which is the right side in this case. Still the ball attachment have recorded higher mean micro-strains when compared to the CMLOC but was not statistically significant which indicates that the CMLOC attachment would release faster than the ball atatchemnt.

When comparing the mean micro-strain induced during bilateral loading for the overdenture retained by both attachments; the CM LOC attachment and the Ball attachment, it was found that $\mathrm{CM}$ LOC attachment have shown a higher statistically significant mean microstrain than the ball attachment, that is mainly due to that when loads are applied bilaterally and the CM LOC attachment 
seems to disengage from one side the load on the other sides prevents such disengagement so the result will be that all stresses will be induced to the underlying implant and despite the fact of improving the stability of the denture. While for the ball attachment, it will not disengage easily, and so when loads are applied bilaterally there tends to be a rotational movement of the denture, and so less forces transmitted to the underlying implant.

\section{CONCLUSIONS}

\section{Within the limitation of this invitro study}

It can be concluded from this invitro study that the newly introduced attachment the CM LOC tends to show a better performance with regards to the micro-strains induced around the implants. On the other hand the ball attachments tends to show more micro-strain around the implants.

As there is no one attachment that would fulfill the ideal requirements, because each clinical situation is unique, so careful selection of attachment is necessary to satisfy the patient's needs and expectations, as well as establishing a long term biologic and functional result.

\section{RECOMMENDATIONS}

Further randomized clinical trials with large sample size comparing the Ball attachment and CM LOC attachment for asingle implant retained overdenture, and evaluating many outcomes; patient satisfaction, quality of life ,maintenance, retention $^{(18)}$, in order to evaluate the performance of CM LOC attachment as the randomized clinical trials are very few for this type of attachment.

\section{REFERENCES}

1. AbdelAal M, Fayyad A, Sheta N, Abdel Nabi N, El Far MM. Related Quality of Life in Single Implant Mandibular Overdenture Retained by CM LOC versus Ball Attachment: A Randomized Controlled Trial. Open Access Maced J Med Sci. 2019 Oct;7(21):3642-3663.
2. Abdelfattah M Y, Fahmi M K .Evaluation of Two Different Attachment Systems Used with Mandibular ImplantRetained Overdenture. OHDM.2019; 18(5):1-6.

3. Abdelhamid AM, Assaad NK, Neena AF. Three dimensional finite element analyses to evaluate stress distribution around implant retained mandibular over denture using two different attachment systems. J Dent Health Oral Disord Ther. 2015;2(5):171-176.

4. Abi Nader S, De Souzan R.F, Fortin D, De Koninck L, Fromentin O, Albuquerque Junior RF., Effect of simulated masticatory loading on the retention of stud attachments for implant overdentures. J Oral Rehabil., 2011 Mar ; 38(3):157-160.

5. Abu Taleb FA, Abel-Aal ZM. Study of locators attachment effect in implant-assisted complete lower over denture opposed with dentulous versus edentulous upper arch. Tanta Dent J 2017;14(8):139-147.

6. Akca K, Cavusoglu Y, Sagirkaya E, Cehreli MC. Earlyloaded one-stage implants retaining mandibular overdentures by two different mechanisms: 5-year results . Int J Oral Maxillofac Implants.2013;28:824-30.

7. Al-qutaibi AY. Attachments Used With Implant Supported Over Denture. Adv Dent \& Oral Health. 2016 ;1(2):71-73.

8. Al-Magaleh WR, Swelem AA, Radi IAW.The effect of 2 versus 4 implants on implant stability in mandibular overdentures: A randomized controlled trial. J Prosthet Dent. 2017 Dec; 118(6):725-731.

9. Alsourori AA, Mostafa MH, kaddah AF. Impact of single implant versus two-implant mandibular retained overdentures on retention and success rate in totally edentulous patients. A Randomized Controlled Clinical Trial. Journal of osteointegration September 2018; $10(3): 32-35$.

10. Aroso C, Silva AS, Ustrell R, Mendes JM, Braga AC, Berastegui E, Escuin T. Effect of abutment angulation in the retention and durability of three overdenture attachment systems: An in vitro study. J Adv Prosthodont. 2016 Feb;8(1):21-22.

11. Barai GD, Jaju SB, Tidke DJ , Rathi NH. Review article FEM analysis of single implant retained mandibular overdenture with four different attachment types: A review. Int Health Biomed Res 2016;4(5):29-34.

12. Bassit $R$ and Lindstrom $H$. in-vivo registration of force development with ceramic and occlusal resin occlusal 
materials on implant supported prosthesis. Int $\mathrm{J}$ Oral Maxillofac Implant 2013: 17(5):17-22.

13. El-Abd M F, El-Sheikh M M, El-Gendy N. Effect of position of single implant with two different attachments on stress distribution of mandibular complete overdenture (in-vitro study).2018;6(2):63-69.

14. Harder S, Wolfart S, Egert C, Kern M. Three-year clinical outcome of single implant-retained mandibular overdentures--results of preliminary prospective study.J Dent. 2011 Oct; 39(10):656-61

15. Reda KM, El-Torky IR, El-Gendy MN. In vitro retention force measurement for three different attachment systems for implant-retained overdenture. J Indian Prosthodont Soc. 2016;16(4):380-385.

16. Mahoorkar S, Bhat $S$, Single implant supported mandibular overdenture: A literature review. J Indian Prosthodont Soc. 2016 Jan-Mar; 16(1): 75-82.

17. Kanazawa M, Tanoue M, Miyayasu A, Takeshita S, Sato D, Asami M, Lam TV, Thu KM, Oda K, Komagamine Y, Minakuchi S, Feine J. The patient general satisfaction of mandibular single-implant overdentures and conventional complete dentures: Study protocol for a randomized crossover trial. Medicine (Baltimore). 2018 May; 97(20):e10721.
18. Cheng T, Sun G, Huo J, He X, Wang Y, Ren YF.Patient satisfaction and masticatory efficiency of single implantretained mandibular overdentures using the stud and magnetic attachments.J Dent. 2012 Nov; 40(11):10181023.

19. Naguib AA, El Khouazat NS, El Monaem AA. Cost Effectiveness of CMLOC Attachment versus Ball Attachment Retaining Single Implant Mandibular Overdentures. Open Access Maced J Med Sci. 2019 Oct 10;7(21):3655-3658.

20. Kono K, Kurihara D, Suzuki Y, Ohkubo C. In vitro assessment of mandibular single/two implant retained overdentures using stress-breaking attachments. Implant Dent. 2014; 23(8):456-462.

21. ELsyad MA, Agha NN, Habib A A. Retention and Stability of Implant-Retained Mandibular Overdentures Using Different Types of Resilient Attachments: An In Vitro Study. 2016 ;31( 5):1040-1048 .

22. Rady A A and Abdel Nabi N. Stress analysis of two different attachments for a two implant retained mandibular overdenture .2017: 63, 3447:3457.

23. El-Abd M F, El-Sheikh M M, El-Gendy N_.Effect of position of single implant with two different attachments on stress distribution of mandibular complete overdenture (in-vitro study).2018;6(2):63-69. 